\title{
Oxigenoterapia en el sufrimiento fetal
}

\author{
Por el doctor C. R. Silva-Mojica \\ Ex-Jefe de Clínica Obstétrica.
}

Con bastante frecuencia hemos empleado el oxígeno en el sufrimiento fetal. Presentamos tan sólo dos historias clínicas con el único fin de divulgar este método, que aplicado en determinadas circunstancias produce buenos efectos: evita acudir a medidas radicales e intempestivas, con perjuicio para la madre; calma la aprehensión de algunos obstetras ante "ruidos fetales velados y expulsión de meconio"; y asegura la supervivencia del feto.

Histonia No. 1.-L. de S.; 32 años; antecedentes obstétricos: dos partos de término, normales, espontáneos, con fetos vivos; gemelar el primero.

Embarazo actual: última regla, junio 16 de 1951. Evolución normal. Parto: mayo 26 de 1952, atendido en la Clínica de Marly. Trabajo normal; con 6 centímetros de dilatación cervical se produce ruptura precoz de las membranas con expulsión del líquido teñido de meconio; los ruidos fetales se hacen lentos y velados. Trasladada la paciente a la sala de partos se encuentra dilatación de seis centímetros, cuello blando, presentación de vértice alta, sin tendencia al encajamiento, contracciones uterinas de gran intensidad y frecuencia. Aunque el cuello llega fácilmente a completar la dilatación, rechazamos la insinuación de aplicación de forceps debido al no encajamiento de la presentación. Por tal motivo decidimos la cesárea abdominal de urgencia motivada por el sufrimien to fetal, con tal mala fortuna de no encontrar en ese momento sala de cirugía disponible por haber operaciones en todas. Se aplica entonces a la paciente mas carilla con oxígeno a cuatro litros por minuto y resolvemos esperar a que alguna de las salas quedara libre para hacer pasar nuestra paciente. Mientras tanto ésta continúa con trabajo intenso, ruidos fetales un poco mejor aunque no nor males y presentación no encajada.

Una hora y media más tarde se daba comienzo a la cesárea bajo anestesia con ciclo-O2. Se obtiene un feto masculino de 3.500 gramos con una circular apretada en el cuello, que presenta cierta dificultad para respirar. Siete días más tarde tanto el niño como la madre salían de la clínica en buenas condiciones.

Historia No. 2.-M. de L.; primigestante de 27 años, atendida en la Clínica La Magdalena, el 14 de abril de 1952. Embarazo normal de término. In- 
gresa a la clínica el 12 de abril iniciando trabajo apenas, el cual se hace luego irregular: hipertonía uterina marcada, con poca tendencia a progresar la dilatación cervical. Se aplican sedantes y antiespasmódicos: Atrinal, Seconal y Demerol intravenoso. Con cerca de treinta horas de trabajo irregular los ruidos futales se hacen notoriamente velados y lentos. Al T. V. se encuentra 7 centímetros de dilatación; bolsa buena; presentación de vértices no encajado. El feto parece grande sin que exista desproporción debido a la pelvimetría satisfactoria de la madre. Se aplica entonces mascarilla con oxígeno a cuatro litros por minuto; como la mejoría del estado fetal es notoria se resuleve esperar un poco más que avance la dilatación del cuello y se produzca el encajonamiento. Se practica ruptura artificial de las membranas.

Dos horas más tarde la dilatación es completa pero la presentación no muestra tendencia a descender. En estas condiciones, con ruidos fetales normalizados por el oxígeno, se intenta una aplicación de forceps en O. I. A, en el estrecho superior, la cual se lleva a cabo bajo anestesia con ciclo-O2 sin contratiempo ninguno y se obtiene un feto masculino de 3.700 gramos en buen estado. Seis dias más tarde, tanto la madre como el niño salen de la clínica en buenas condiciones.

\section{COMENTARIOS}

La primera historia nos demuestra cómo el oxígeno sostiene la precaria vitalidad de un feto amenazado por una circular apretada del cordón, por un tiempo prolongado relativamente, hasta que las circunstancias permiten efectuar una operación cesárea. Es posible que sin este recurso el niño hubiera nacido muerto o en muy malas condiciones.

En el segundo caso, vemos cómo el oxígeno mejora las condiciones fetales en tal forma que hace posible una espera prudencial para permitir el parto por vía vaginal. Sin esta medida es posible que se hubiera apelado a conductas precipitadas: cesárea, dilatación artificial del cuello, forceps alto, etc.

Nos ha movido a ensayar el oxígeno en la asfixia intrauterina el hecho de que Richard Turpin, en University Hospital of Augusta. Ga. lo usa sistemáticamente en casos como trabajos prolongados, trabajos irregulares por inercia u otras distocias de la contracción y sufrimiento fetal manifestado ya en irregularidad de los ruidos fetales o en presencia de meconio. Recomienda aplicarlo a cuatro o cinco litros por minuto con sonda o cánula nasal (de las cuales hay diversos tipos en el comercio) humedeciendo el oxígeno por medio de un frasco de Wolf, detalle este importante sobre todo si la oxigenoterapia se aplica por largo tiempo para evitar la deshidratación producida por este gas sobre las mucosas del árbol respiratorio ${ }^{1}$.

Con el oxígeno hemos podido comprobar en el sufrimiento fetal, una acción más aparente y más sostenida que con analépticos cardio-respiratorios tipo dietilamida del ácido 3-piridín carboxílico y penta metileno tetrazol. Es posible que su efecto se deba a una mayor saturación de oxígeno y por lo tanto de oxihemoglobina en la sangre materna, ofreciendo así un mejor aprovechamiento de O2 en la circulación placentaria con repercusión inmediata sobre la vitalidad 
del feto. Por este motivo su acción es mucho más fisiológica que la de las citadas drogas puesto que éstas estimulan transitoriamente los centros bulbares del feto, mejoran tan sólo un síntoma, la frecuencia de los ruidos cardíacos, pero no aportan el elemento vital indispensable como osurre con la oxigenoterapia. Es bien sabido por todos, las lesiones irreparables producidas por la anoxia sobre el tejido nervioso.

Se debe tener en cuenta que no debemos ser exclusivistas con la aplicación de este método, ni pretender que con sólo oxígeno se resuelvan todos los casos del sufrimiento fetal, ya que éste es producido por los más variados fac tores: circulares, nudos, procidencia y brevedades del cordón umbilical; distocias de la contracción; trabajos prolongados; expulsión demorada por resistencia del piso perineal u otras causas; toxicosis gravídica desprendimiento prematuro de placenta normo-inscrtal ${ }^{2}$ y drogas sedantes, hipnóticas y anestésicas en dosis desmedidas. Como se comprende la oxigenoterapia debe ir siempre acompañada o seguida de otras medidas tendientes a combatir la distocia predominante: cesárea, forceps, regularizadores de la contracción uterina, etc., según el caso.

Conviene además dar una justa interpretación a los signos de sufrimiento para evitar medidas inapropiadas: los ruidos fetales se hacen más lentos durante la contracción y a veces cuando se produce el encajamiento ${ }^{3}$. La presencia de meconio en el líquido puede ser índice de sufrimiento actual como también de un estado de sufrimiento anterior, corregido ya por una u otra causa.

Canon, Guilhem y Mayer consideran que antes del nacimiento, los clásicos signos de sufrimiento fetal indican probablemente la culminación y no el principio del proceso de anoxia. Anotan que la oxigenoterapia materno-fetal y post-natal es el medio más eficaz para combatir los efectos de la anoxia pero que es inútil cuando ella va asociada con lesiones orgánicas de centro respiratorio.

Ante este concepto la oxigenoterapia cobra un gran valor como medida profiláctica de la asfixia intrauterina. Finalmente, para asegurar la supervivencia fetal es necesario estar preparados para combatir los efectos de la anoxia en d. recién nacido: aspiración sistemática nasal, traqueal y gástrica; oxígeno y an. tibióticos ${ }^{4}$.

\section{SUMARIO}

Se presentan dos casos de sufrimiento fetal en los que la oxigenoterapia produjo buen resultado.

Se hacen comentarios sobre las causas y tratamientos de asfixia intrauterina y del valor de la oxigenoterapia materno-fetal y post-natal como también de otras medidas que se deben tomar en la anoxia del recién nacido.

\section{BIBLIOGRAFIA}

1.-Escamilla-Blanco J., médico del University Hospital, Augusta Ga. Referencia personal por carta, octubre 13 de 1951.

2.-Silva-Mojica. Sufrimiento Fetal. Tesis de grado. Universidad Nacional, 1945. Pág. 45.

3.-Moragues Bernat. Clínica Obstétrica. Ed. III, pág. 114.

4.-Bull. Fed. Soc. Gynec. et Obst., 4: 145-242, 1952. Citado por Year Book of Obst. and Gynec., págs. 266-267, 1952. 